\title{
Cotidiano e configuração de espaços de aprendizagem
}

\section{Quotidian and configuration of learning places}

\author{
Cleci Maraschin* \\ Jaqueline Tittoni** $^{* *}$
}

\begin{abstract}
RESUMO
Este artigo toma o conceito de cotidiano como analisador operativo capaz de produção de leituras e de criação de modos de intervenção social. Ao pensar o cotidiano no âmbito das relações de poder e da constituição da autonomia, procuramos explorar os poderes invisíveis e as práticas anônimas na sua possibilidade de invenção, criação e transformação social. Consideramos como referência reflexiva uma proposta de estágio em Psicologia Social, a fim de problematizar a formação acadêmica e explorar as conexões entre trabalho e educação na produção de modos de intervir e de produzir conhecimento no campo social.

Palavras-chave: cotidiano, autonomia, formação acadêmica.
\end{abstract}

\begin{abstract}
This paper takes up the concept of quotidian as an operative analyzer capable to produce readings and create forms of social intervention. We think of quotidian in the scope of the discussions concerning power and autonomy, seeking to explore invisible powers and anonymous practices in their potentiality for social invention, creation and transformation. We
\end{abstract}

* Doutora em educação/UfRGS, Professora do Instituto de Psicologia/UFRGS. cmar@ufrgs.br

** Doutora em Sociologia/UFRGS, Professora do Instituto de Psicologia/UFRGS. jaquemim@terra.com.br 
consider as a reference for reflection an internship proposal in social psychology, in order to query college schooling and explore the connections between work and education in the production of manners of intervention and production of knowledge in the social field.

Key-words: quotidian, autonomy, college schooling.

\section{Reinventando a formação}

A formação de profissionais nas áreas humanas e sociais tem implicado revisitar as práticas e os espaços de aprendizagem já consolidados, na medida em que as transformações sociais e sua velocidade estão sempre a perturbar noções que se pretendiam universais e permanentes, dessa forma, configurando uma necessária problematização do que se poderia adjetivar de "práticas tradicionais" da formação. Essa problematização pode ser pensada em dois planos. O primeiro deles consiste no questionamento da polarização teoria $\mathrm{x}$ prática. A maioria das práticas realizadas em diversos âmbitos institucionais tem se efetivado, principalmente, na perspectiva de uma "aplicação" dos conhecimentos teóricos adquiridos nos bancos das salas de aulas em disciplinas anteriores. Tudo se passa como se a formação básica fundamentasse a atuação profissional e essa última, condicionada pelo campo empírico, instituísse as especialidades tradicionais: psicólogo clínico, psicólogo organizacional e psicólogo escolar. Além da dicotomização teórico-prática, é necessário questionar também o quanto as noções tidas como básicas estão ancoradas em perspectivas teóricas que enfatizam a centralidade do indivíduo, a normatização das condutas, a adaptação às configurações institucionais. Essas tendências constituintes de uma totalidade disciplinar não abarcam a multiplicidade de saberes/conhecimentos da experiência cotidiana - saberes advindos de planos que se situam fora do discurso acadêmico, mas que produzem efeitos de perturbação, abrindo brechas inventivas, produzindo singularidades e modos de existência.

Neste artigo, pretendemos discutir a importância da análise do cotidiano para a compreensão e intervenção no plano social, tendo como base a proposição e implementação, no âmbito do curso de formação de psicólogos da Universidade Federal do Rio Grande do Sul, de uma proposta de estágio, 
denominada de "estágio em psicologia social". ${ }^{1}$ Diferindo das experiências tradicionais que experimentávamos como supervisoras de estágios de psicologia escolar e de psicologia do trabalho, projetamos o referido estágio como uma atividade que se definiria e se construiria com seu próprio processo. Uma atividade com um espaço e um tempo permeáveis, tecidos provisoriamente na contingência da intervenção e conhecimento do encontro entre o conhecimento acadêmico e os saberes cotidianos, com sua duração outra, capaz de produzir diferenças. Espaço-tempo permeável, de conexões entre diferentes temporalidades e experiências. O desejo inicial era o de fazer conexões, entre professores, entre práticas instituídas, entre conhecimentos, entre os ditos conhecimentos básico e aplicado. O intuito era experienciar um processo de trabalho e conhecimento que ultrapassasse as dicotomias por nós tão criticadas, engajando um maior número de professores e de alunos, dedicando para isso um maior período de tempo.

A aventura de conhecer e trabalhar além do abrigo oferecido pelas relações instituídas nas outras experiências suscitou a criação do espaço de estágio, configurado como importante dispositivo para potencializar produções acadêmicas sensíveis a fluxos inusitados. Necessitamos de modos de conhecer e trabalhar que afirmem a complexidade e apontem na direção de detectar tendências, movimentos, direções. Modos que estejam também aliados a um compromisso ético com o processo de singularização e de diferenciação processo esse que no campo educativo poderia ser identificado como o processo de autoria de pensamento e no campo do trabalho como autogestão.

Necessitamos modos de trabalhar e de conhecer que mobilizem outras sensibilidades, ampliando os focos da razão e da possibilidade. A noção mesma de cotidiano introduz no campo do trabalho e do conhecimento outras visibilidades, na forma das "práticas anônimas", dos modos tácitos do conhecer, viver e sobreviver, por exemplo. CERTEAU (2000) propõe a análise das práticas cotidianas não através da oposição entre o popular e o científico, mas como "práticas anônimas" que buscam visibilidade e legitimidade no campo social. Essas práticas são produzidas em campos de força, cujos fluxos e mo-

1 Esse estágio surgiu no ano de 1998. Trata-se de um estágio alternativo aos anteriormente denominados "estágio de psicologia escolar" e "estágio de psicologia do trabalho". Tem uma duração de 18 meses, período no qual os alunos desenvolvem seu trabalho em uma sede institucional de alguma comunidade, a fim de alcançar a rede social aí existente - escola, centros comunitários, conselho tutelar, abrigos, postos de saúde etc. Ao final do estágio, além de uma monografia, o grupo organiza uma atividade de extensão universitária que pode ter um caráter de encontro científico ou de cursos de capacitação de agentes sociais. 
vimentos, no sentido da legitimação e da invenção, não cessam de produzirse e pressionar para delimitação de espaços de visibilidade.

Este artigo também concretiza um esforço no sentido de organizar um percurso teórico, definindo ferramentas conceituais capazes de produzir leituras do social e sustentar intervenções.

\section{O cotidiano como potência}

O cotidiano se institui como objeto nos estudos do campo social em contraposição às análises pautadas na estrutura e nos indicadores socioeconômicos. No bojo das discussões sobre os movimentos sociais, principalmente a partir da década de oitenta, os estudos sobre o cotidiano buscam visibilizar modos de viver produtores da vida social. Ao se analisar os modos de viver de um coletivo, faz-se uma crítica à perspectiva estruturalista da análise do social, já que essa última entende ser possível compreender a sociedade e seus sujeitos principalmente através de indicadores socioeconômicos. O estudo dos modos de viver potencializa análises da condição dos sujeitos, ao colocar em evidência as contingências sociais de sua produção, construindo um laço interessante entre a Psicologia e o social. Traduzidos na noção de experiência e de cotidiano, os modos de vida explicitam as formas de apropriação e de produção da existência que se esboçam nas mínimas brechas sociais. Lá, onde o poder legitimador do Estado, da Lei e da Ciência exerce outros domínios.

Ao associar o estudo do cotidiano com as práticas populares, problematizamse as estruturas legitimadas que têm poder para definir até mesmo os modos "corretos" de viver, e produz-se, no espaço da cultura, formas de expressão de modos de viver pulsantes, apesar de sua não legitimação institucional.

A essa potencialidade, de pressionar para abertura de espaços de invenção e de criação, é que se pretende dar visibilidade. Assim, pretende-se estudar o cotidiano não como forma acabada de produção de modos de viver, mas como algo capaz de produzir inquietações nos nossos modos de viver e de trabalhar, configurando possibilidades outras de criação e de existência.

A noção de cotidiano também contempla a dimensão de poder nos moldes foucaultianos; a idéia de poderes múltiplos, capilares, que se produzem para além das legitimações do Estado, da Lei e da Ciência. Poderes que, nas 
lutas por legitimação, adquirem ou não visibilidade. Mesmo invisíveis, pulsam e causam efeitos de produção de vida, nem sempre reconhecidos imediatamente (FOUCAULt, 1989). Na discussão sobre o trabalho ou sobre a educação, isso é evidente. O que gera a chamada "motivação" para o trabalho ou para a aprendizagem nem sempre está associado às estratégias gerenciais ou pedagógicas, mas reside no reconhecimento social, no convívio com os colegas, na função do trabalho para a sobrevivência, na perspectiva de uma melhora social.

A dimensão do poder organiza as análises do cotidiano, de modo a que se pense o cotidiano como efeito de lutas de poder, como atravessado por estratégias e táticas que produzem movimentos de visibilidade ou invisibilidade, de legitimação ou refutação de modos de viver. Entrelaçam-se as pressões econômicas e sociais com os projetos e desejos, de modo a configurar espaços provisórios - territórios - negociados, atualizados, configurados constantemente.

DE CERTEAU (1998, p. 103-104) sugere pensar as práticas cotidianas como táticas. "Habitar, circular, falar, ler, ir às compras ou cozinhar, todas essas atividades parecem corresponder às características das astúcias e das surpresas táticas: gestos hábeis do "fraco", na ordem estabelecida pelo "forte", arte de dar golpes no campo do outro, astúcias de caçadores, mobilidades de manobras, operações polimórficas, achados alegres, poéticos e bélicos".

O estudo do cotidiano, assim, coloca-se na sua potencialidade de evidenciar jogos de poder e regimes de verdade, sendo sobretudo importante para uma análise dos modos como operam tais jogos e regimes na produção da vida. Visto que pode expressar os elementos invisibilizados nos jogos de poder, a potencialidade do estudo do cotidiano reside em indicar, sobre o anônimo, aquilo que não possui estatuto de expressão e de legitimação. Não por acaso, o estudo das culturas e práticas populares toma a análise do cotidiano como importante referência, mas sua potencialidade não está restrita a esse campo. Pressionar os poderes legitimados, para possibilitar a produção de práticas outras, evidenciando brechas por onde possam passar a invenção e o "invisível": isso é o que se quer traduzir na discussão acadêmica e trazer para a formação profissional, no momento em que se introduz os estudos sobre o cotidiano e sobre os modos de viver.

Essa experiência diferenciada de estágio, afetada por práticas cotidianas e pensada como uma estratégia de poder, reconfigura a realidade, subtraindo-a de sua mesmice e previsibilidade, deixando a mostra um campo coletivo e disperso de forças heterogêneas, com conexões que se fazem e se desfazem segundo os vetores dessas mesmas forças. 


\section{A experiência: operando conceitos}

Esse campo de forças "corporifica-se" nessa experiência junto a dois coletivos da Vila São José, em Porto Alegre: a Griffe do Morro da Cruz e o Centro Infanto-Juvenil Murialdo. ${ }^{2}$

A Griffe do Morro da Cruz é formada por um grupo de costureiras da comunidade. Iniciamos o trabalho de estágio em julho de 1998. Desde então, temos acompanhado os movimentos desse grupo em direção à autogestão e à afirmação de seu trabalho e de sua condição, na comunidade da Vila São José e na cidade de Porto Alegre. O grupo, no momento, é formado por seis costureiras que trabalham com patchwork, uma técnica de reciclagem para confecção de roupas. Elas utilizam retalhos doados por empresas da área da tecelagem e pela comunidade em geral. Esse grupo possui importante visibilidade na mídia e está integrado à rede de produção e de economia popular, sendo solidário junto a outros grupos de autogestão da cidade.

Os três anos de atividade junto à "Griffe" têm demonstrado que os processos de produção da autogestão são construídos no cotidiano do trabalho e na trajetória dos grupos, de uma forma que não é linear nem imediata. $\mathrm{O}$ movimento/deslocamento entre as posições de mulheres, costureiras, moradoras da Vila São José, recria trajetórias e refaz caminhos na produção de modos de trabalhar solidários. Esses modos de viver cotidianos das costureiras mobilizam nossa atenção e definem espaços e tempos de trabalho conjunto possível. Potencializar suas produções coletivas e seus movimentos no sentido da autogestão, mostrou-se uma estratégia eficiente, também capaz de orientar estas produções em Psicologia Social, instigando a invenção de tecnologias outras que atualizam intervenções coletivas. Potencializar espaços de troca, onde se ensina o que se sabe, apesar de aparentemente ser uma estratégia simples, pode trazer uma série de conseqüências importantes, pois instiga ao trabalho menos parcializado e especializado. Na prática, quem sabe costurar aprende a bordar, quem sabe cortar moldes ensina quem sabe fazer crochê. Não se forjam espaços de cooperação e solidariedade sem a troca e o reconhecimento mútuo dos saberes e das capacidades dos componentes dos grupos. Laços de respeito e admiração acabam por instigar sensibilidades que

2 No período relatado neste artigo, foram estagiários os seguintes acadêmicos: Alex Coromberque, Daniel Smith, Eliane Jover, Elizângela Zaniol, Laura Gonçalves e Paula Sandrini Leite. 
sustentam os espaços de troca e de solidariedade. Temos aprendido, também, que os espaços de trabalho são múltiplos e expandem as fronteiras dos tradicionais locais e grupos de trabalho. A fixidez e a rigidez que a organização capitalista imprimiu ao trabalho é apenas sua face mais visível, pois passam pelo trabalho outros fluxos, como os modos de inscrição na cidade e a possibilidade de integrar outras redes sociais. As mulheres da "Griffe" mostraram interesse em trabalhar com os grupos de costura dos pacientes do Hospital Psiquiátrico São Pedro, participam da rede de Economia Solidária da cidade, gostam de fazer piquenique no parque, de ir ao teatro. Movimentos que definem outros domínios e outros espaços que podem ser potencializados através do trabalho. São intervenções que convivem, criam, pensam o cotidiano, intervenções simples mas que potencializam uma economia de trocas e de sensibilidades.

A atividade junto ao Centro Infanto-Juvenil Murialdo (CIJM) iniciou-se em março de 1999. ${ }^{3} \mathrm{O}$ centro presta atendimento socioeducativo à crianças e adolescentes em turno inverso ao escolar. As atividades do centro são coordenadas e financiadas pela Fundação de Assistência e Serviço Social da prefeitura de Porto Alegre (FASC) e pela Mitra Arquidiocese de Porto Alegre - Paróquia São José do Murialdo. Atualmente, ele atende um grupo de 120 crianças, dividido em dois turnos. Conta com um padre dirigente e uma equipe profissional formada por uma pedagoga e dois estagiários de Psicologia. Trabalham como educadores 10 pessoas entre seminaristas, contratados e voluntários. Como pessoal de apoio, o centro conta com uma merendeira e uma faxineira.

Nesses dois anos de trabalho conjunto, pode-se destacar alguns frutos. Talvez um dos primeiros seja a ressignificação e reinvenção do trabalho de educador. As educadoras populares, por serem oriundas da comunidade e sem formação específica, desvalorizavam seu trabalho. Era comum dizerem "eu trabalho no centro pois não sou capaz de trabalhar em outro lugar". A potencialização de seu próprio fazer, a possibilidade de estabelecer um sistema de trocas entre elas próprias, o apoio e a experimentação de modos de educar não enquadrados em uma proposta pedagógica escolar, a inclusão de outras atividades no âmbito educativo (cozinheira, faxineira) foram fatores potencializadores de uma autoria propositiva com efeitos institucionais que

3 Outra reflexão sobre esse estágio pode ser encontrada em COROMBERQue, A. et al. Interrogações sobre o fazer psicológico. Entre Linhas, n. 6, jan./fev., 2001. Publicação do CRP 07. 
extrapolam sua atividade com os alunos. A inclusão, no cotidiano dos educadores, de encontros com as famílias, com o conselho tutelar, com as escolas e com outras instituições da comunidade possibilitou uma ressignificação da abrangência social do atendimento prestado (em termos educacionais e de saúde). A ampliação e a implicação de seu trabalho com as demais instituições sociais produziu uma nascente idéia de rede social. Outra dimensão do trabalho, em permanente prática cotidiana, consistiu em possibilitar um diálogo entre valores religiosos, populares e acadêmicos, explicitando as diferenças, os possíveis modos de convivência, as relações de poder.

Os dois coletivos que foram trabalhados são efeitos de transformações sociais importantes nos modos de trabalhar e de educar. Pode-se pensá-los como metamorfoses dos mesmos: produzindo vestimentas e práticas educativas, com uma relativa criatividade em relação aos modos formais de trabalho e educação, as costureiras e as educadoras não chegam a problematizar os processos de precarização forjados na história social do trabalho. A emergência de coletivos, como a Griffe do Morro da Cruz, dá-se, ao mesmo tempo, como necessidade de geração de renda e de trabalho e como alternativa aos modos tradicionais (leia-se competitivos, parcializados, seccionados) de organizar o trabalho. O trabalho desliza de sua morada tradicional (a fábrica), se inscreve no "fora", na vida em comunidade, no centro comunitário, na rua e pressiona para outras intervenções no campo das ciências humanas. Do ponto de vista da educação, a experiência junto ao Centro Infanto-Juvenil Murialdo, que educa sem ser escola, também traduz um deslizamento, apontando uma mudança na morada tradicional da educação (leia-se escola, Pedagogia... enfim). Os educadores aparecem como um mix de professores, amigos, vizinhos pressionando para a invenção de outros agenciamentos entre o ensino e a aprendizagem. Para além de pensar estas alternativas como modo de "ocupar" as crianças quando a escola já não se ocupa delas, potencializa-se a invenção e outros modos de conhecer, tendo presente, pelo menos na nossa experiência, a potência dos modos tradicionais que pressionam para a simples reprodução do modelo escolar. Da mesma forma, com relação ao trabalho, potencializa-se a invenção de outros modos de trabalhar pautados na solidariedade e na autogestão, reconhecendo também a potência dos modos tradicionais de trabalhar.

A experiência com ambos os grupos visibilizou uma complexa organização comunitária permeável ao trabalho em conjunto com a Universidade. Nessa perspectiva busca-se, atualmente, articular as diferentes iniciativas coletivas autogeridas - associação de moradores, grupos de geração de renda -, formando uma rede social com instituições públicas e religiosas que prestam 
serviços sociais - escolas, postos de saúde, conselho tutelar, centro murialdino. O estágio em psicologia social já está se constituindo em uma via importante de articulação, de diálogo e de reconhecimento da potencialidade colaborativa da Universidade, no sentido de apoiar e capacitar grupos emergentes. Como fruto dessa interface, pode-se citar a elaboração de conhecimentos capazes de articular e produzir efeitos de emancipação coletiva, dentre eles, a constituição de uma metodologia de intervenção social.

A definição desses espaços e tempos de trabalhos possíveis mostra-se como encontros e tensões, como campos de força em que o encontro com a diferença orienta trajetos desenhados na perturbação, no tensionamento, na problematização do dado passado no sentido do desejo-potência que abre espaço para o movimento. Trilhar, desenhar o trajeto entre as pressões econômicas e culturais, inventar fluxos em campos de força já legitimados e instituídos indicam os movimentos não só dos grupos que foram trabalhados, mas o próprio trabalho educador. Formar é um ato de pressionar, moldar, ao mesmo tempo em que é também um movimento no sentido de organizar, produzir, operar.

\section{Conhecimento inventivo}

Criar interfaces naquilo que se adjetiva de "social", ou seja, a convivência com cotidianos institucionais diferenciados dos tradicionais, mas múltiplos e heterogêneos, propicia a emergência de espaços de aprendizagem inusitados. Nos casos aqui relatados, propiciou-se a aprendizagem em estágio não como um momento na ordem evolutiva do formar-se psicólogo, mas como um experienciar de um processo de trabalho e de conhecimento agenciador de intervenções em Psicologia Social.

Ao tomar-se os modos de viver, que se realizam no cotidiano, como um objeto psicológico de escuta e intervenção no plano do social, é necessário considerar sua estrutura simbólica, histórica e auto-organizativa (IBAÑES, 1994).

Os modos de existir (educador popular, criança-adolescente que freqüenta o centro, costureira da Griffe, seminarista, estagiário de Psicologia) possuem uma natureza simbólica e não "natural", podendo ser definidos a partir do tipo de relação que os captura e os constitui no plano dos significados compartilhados. Esta dimensão implica entender também o simbólico 
como operador gerativo de realidades existenciais, nas quais movimento e paralisação constituem modos de seu operar. A condição de existência humana não é essencialista, mas é sempre contingente ao seu modo de operar em deriva com a sua circunstância.

Além de simbólico, os modos de existência são históricos. E isso não significa somente admitir que existe uma história desses modos, mas, mais radicalmente, que eles têm uma memória. Ou seja, que esta memória participa da história de sua produção, fazendo com que as formas presentes abram, sem no entanto determinar, as possibilidades do que acontecerá, sem esquecer que os agenciamentos presentes retroagem reflexivamente, transformando, reconceituando o já vivido.

Poderia-se agregar aqui o aspecto auto-organizativo, ou autopoiético (maturana, 1997) dos modos de existir. Aspecto que conduz ao incremento da complexidade interna, transformando as contingências vindas da diferença em processos (des) estruturantes. Uma das características mais interessantes é a imprevisibilidade das transformações que experimentam as modalidades de existir (questionando muitas das práticas avaliativas e preditivas da Psicologia). O que não significa uma falta ou uma falha do sujeito ou da instituição (conhecimento, estrutura, precisão), mas uma sensibilidade às influências aleatórias bem como à criatividade na construção de possibilidades de soluções distintas das esperadas.

Um último ponto a destacar refere-se ao fato de que esses modos de existir estão configurados ou tencionados pelo que IBAÑES (1994) denomina de agência humana. A atividade humana é propositiva, intencional, o que implica em reconhecer que nenhuma condição é ontogeneticamente suficiente para produzir um efeito ou um modo de existência determinado. Essa é uma potencialidade definidora de uma atitude de intervenção de profissionais das Ciências Humanas em comunidades ditas "carentes". Pois ao serem assim adjetivadas, estariam destituídas de qualquer possibilidade inventiva, criativa.

Fazer com que esses múltiplos cotidianos operem efeitos no cotidiano universitário possibilita a produção de aprendizagens que não se configuram somente na busca de soluções aos problemas - aprendizagem reativa, ou aplicativa -, mas que se configuram em um espaço inventivo e criativo no qual é possível compor novas problemáticas e experimentar metodologias de intervenção pró-ativas. Se o estágio configura-se em uma experiência desafiadora, revigorante, então ele não é menos problemático, dada a complexidade do objeto de estudo e de intervenção. Como ressignificar esse caos que adentra pela fenda, sem adaptá-lo ou expurgá-lo por meio de práticas e de sistemas de 
sentido prévios? Trata-se de construir conhecimento no processo mesmo da intervenção.

Capturar esses movimentos nos processos de trabalho e de conhecimento requer mobilizar sensibilidades anônimas, cujos estatutos de legitimidade ainda residem nas experiências pessoais referenciadas em uma psicologia do indivíduo. Traduzir essas sensibilidades como elementos ativos na formação de psicólogos sociais, agenciadores de intervenções no campo social, é uma prática que iniciamos nesse estágio.

Os efeitos nos modos de organizar o trabalho acadêmico também são evidentes, sendo a supervisão um exemplo importante. A supervisão organiza-se no sentido da criação de coletivos onde o conhecimento pode circular e produzir-se como uma experiência de troca, potencializando a invenção de espaços e de tempos de conhecer e trabalhar em Psicologia. Essa atitude criativa, na qual se engajam professores e alunos causará uma reinvenção do próprio cotidiano acadêmico.

\section{REFERÊNCIAS}

CERTEAU, M. A invenção do cotidiano. Rio de Janeiro: Vozes, 2000.

FOUCAULT, M. Microfísica do poder. Rio de Janeiro: Graal, 1989. IBAÑES, T. Psicologia social construcionista. México: Universidad de Guadalajara, 1994.

MATURANA, H. R.; VARELA, F. J. De máquinas e seres vivos: autopoiese - a organização do vivo. Porto Alegre: Artes Medicas, 1997.

Texto recebido em 10 fev. 2002

Texto aprovado em 22 abr. 2002 